\title{
A novel system for on-farm fertility monitoring based on milk progesterone
}

\author{
Ines Adriaens, ${ }^{* 1}$ Wouter Saeys, ${ }^{*}$ Tjebbe Huybrechts, ${ }^{*}$ Chris Lamberigts, $†$ Liesbeth François, $\ddagger$ \\ Katleen Geerinckx,§ Jo Leroy,\# Bart De Ketelaere, ${ }^{*}$ and Ben Aernouts*ll \\ *Department of Biosystems, Division of Mechatronics, Biostatistics and Sensors (MeBioS), \\ †Department of Biosystems, Livestock Physiology, and \\ ‡Department of Biosystems, Livestock Genetics, KU Leuven, Kasteelpark Arenberg 30, 3001, Heverlee, Belgium \\ §Province of Antwerp, Hooibeekhoeve, Hooibeeksedijk 1, 2440 Geel, Belgium \\ \#Faculty of Pharmaceutical, Biomedical and Veterinary Sciences, University of Antwerp, Universiteitsplein 1, Wilrijk, Belgium \\ \|Department of Microbial and Molecular Systems, Cluster for Bioengineering Technology, KU Leuven, Campus Geel, 2440 Geel, Belgium
}

\begin{abstract}
Timely identification of a cow's reproduction status is essential to minimize fertility-related losses on dairy farms. This includes optimal estrus detection, pregnancy diagnosis, and the timely recognition of early embryonic death and ovarian problems. On-farm milk progesterone $(\mathrm{P} 4)$ analysis can indicate all of these fertility events simultaneously. However, milk P4 measurements are subject to a large variability both in terms of measurement errors and absolute values between cycles. The objective of this paper is to present a newly developed methodology for detecting luteolysis preceding estrus and give an indication of its on-farm use. The innovative monitoring system presented is based on milk P4 using the principles of synergistic control. Instead of using filtering techniques and fixed thresholds, the present system employs an individually on-line updated model to describe the P4 profile, combined with a statistical process control chart to identify the cow's fertility status. The inputs for the latter are the residuals of the on-line updated model, corrected for the concentration-dependent variability that is typical for milk $\mathrm{P} 4$ measurements. To show its possible use, the system was validated on the $\mathrm{P} 4$ profiles of 38 dairy cows. The positive predictive value for luteolysis followed by estrus was 100\%, meaning that the monitoring system picked up all estrous periods identified by the experts. Pregnancy or embryonic mortality was characterized by the absence or detection of luteolysis following an insemination, respectively. For 13 cows, no luteolysis was detected by the system within the 25 to $32 \mathrm{~d}$ after insemination, indicating pregnancy, which was confirmed later by rectal palpation. It was also shown that the system is able to cope
\end{abstract}

\footnotetext{
Received September 12, 2017.

Accepted May 9, 2018.

${ }^{1}$ Corresponding author: ines.adriaens@kuleuven.be
}

with deviating $\mathrm{P} 4$ profiles having prolonged follicular or luteal phases, which may suggest the occurrence of cysts. Future research is recommended for optimizing sampling frequency, predicting the optimal insemination window, and establishing rules to detect problems based on deviating $\mathrm{P} 4$ patterns.

Key words: milk progesterone, monitoring fertility, on-line algorithm, statistical process control

\section{INTRODUCTION}

Correct identification of a cow's fertility status is important to further optimize reproductive performance in dairy cattle and consequently enhance farm profitability (Inchaisri et al., 2010). To minimize fertilityrelated losses, it is essential to obtain a complete image of a cow's reproduction status as soon and accurately as possible. This should include information on the onset of cyclicity and estrus, successful inseminations, pregnancy, embryonic loss, and the occurrence of ovarian abnormalities causing fertility problems (Friggens and Chagunda, 2005; Walsh et al., 2011). Today, systems based on external estrous symptoms fail to detect silent estruses, nor are they suitable to identify other fertility events such as pregnancy or acyclicity. This presses the need for a system which combines (silent) heat detection with the detection of pregnancy, embryonic loss, and the presence of ovarian abnormalities (Friggens and Chagunda, 2005).

Milk progesterone (P4) measured over time is widely accepted as a useful parameter to obtain a complete and direct image of a cow's reproduction status (Friggens and Chagunda, 2005; Martin et al., 2013), and an automated system for on-farm measuring milk P4 is already commercially available (Mazeris, 2010). One of the most important challenges is the interpretation of the raw sensor data (Rutten et al., 2013). Milk P4 measurements are subject to a large variability, partly caused by the measurement technique and calibration 
method (Adriaens et al., 2017), the sampling technique, or the fat content in the milk sample (Pennington et al., 1981; Friggens et al., 2008). Additionally, P4 profiles also vary both within and between cows, for example in absolute values, slopes, and lengths, and often show irregular patterns (Meier et al., 2009; Blavy et al., 2016; Bruinjé et al., 2017a). However, a recently developed mathematical model enables characterization of $\mathrm{P} 4 \mathrm{dy}-$ namics, thereby allowing for data-based interpretation of a cow's fertility status (Adriaens et al., 2017).

For milk $\mathrm{P} 4$ to be useful as an indicator for fertility events, the raw $\mathrm{P} 4$ measurements should be converted into specific information, or even better, actions to be taken by the herdsmen on farm. In this context, it is shown that both the variability of the measurements and the variability between estrous cycles should be taken into account (Friggens and Chagunda, 2005; Friggens et al., 2008; von Leesen et al., 2013). In general, this means that the monitoring algorithm should meet following requirements: (1) it should be robust against outliers and different levels of measurement errors, which might be dependent on the measurement and calibration technique (Adriaens et al., 2017); (2) it should be able to discriminate between luteal and follicular concentrations to indicate actions such as insemination, embryonic loss, and possible cyst in an individualized way; and (3) it should be automated and implementable on farm.

The closest attempt to this so far was published in 2005 by Friggens and Chagunda (2005), who developed a biological model to predict the reproductive status of dairy cows based on milk P4. Besides different cowspecific factors, they used the smoothed level of the milk P4 obtained with a multiprocess Kalman filter to account for the variability in the measurements. Next, this level is monitored and when it underruns a fixed threshold, the cow is indicated in estrus and can be inseminated. Although this model has proven to be useful (Friggens et al., 2008) and easy to interpret, it has 2 major disadvantages, also identified in Friggens et al. (2008) and Bruinjé et al. (2017b): (1) the use of a smoothed P4 level causes a lag in the detection moment (dependent on, e.g., sampling frequency and rate of luteolysis); (2) using a fixed threshold on the (smoothed) P4 level provides no flexibility to cope with the variability in individual $\mathrm{P} 4$ levels between cycles. For example, when a measurement fails at the crucial point of luteolysis, the smoothed level is not updated, and the next measurement of low P4 will be marked by this filter as very unlikely. Accordingly, the smoothed P4 level will adapt just moderately. Only when the following measurement is also low, it will move toward follicular P4 concentrations and ultimately undercut the fixed threshold (Bruinjé et al., 2017b). Moreover, this depends on milking and sampling frequency, and may occur for example more than 3 milkings after the actual occurrence of luteolysis, resulting in a large delay on the predicted ideal insemination moment. Additionally, if the follicular P4 concentrations are close to the fixed threshold, the detection lag will be even larger and successful timing of insemination even more unlikely. The mathematical model described in Adriaens et al. (2017) has the potential to overcome these drawbacks, while maintaining the flexibility to deal with various $\mathrm{P} 4 \mathrm{dy}-$ namics, though being robust for measurement-related noise. However, in its current described form, it is not suitable for on-farm monitoring purposes.

The objective of this study was to develop a new approach to monitor fertility based on milk P4 measurements and the concepts of synergistic control (Mertens et al., 2009; Huybrechts et al., 2014; Maselyne, 2016). It was hypothesized that a system which combines a mathematical model to describe the $\mathrm{P} 4$ dynamics (Adriaens et al., 2017) with an on-line updated statistical control chart on the residuals of this model will allow on-line identification of the fertility status of a dairy cow and indicate important fertility events such as estrus, pregnancy, and ovarian problems. Moreover, the proposed approach would be independent of fixed thresholds and does not cause a lag in the description of events such as luteolysis, which would make the system more consistent and less dependent on the sampling rate and measurement errors.

\section{MATERIALS AND METHODS}

\section{Experimental Data}

For this study, both milk P4 data and additional information on reproduction status were collected from the eligible cows on an experimental dairy farm in Geel, Flanders. Two trials in which additional data were collected from the cows were set up in the spring of 2016 and 2017. In both periods, cows were milked automatically with an automated milking system of DeLaval (VMS, Delaval, Tumba, Sweden) and were fed a mixed ration of grass and corn silage, supplemented with concentrates provided in the milking robot and through concentrate feeders. Because the procedure of data collection differed between the 2 periods due to the availability of an on-line milk P4 analyzer (Herd Navigator, Lattec, Hiller d, Sweden) in the second period, each trial is described separately, and the information on cows and $\mathrm{P} 4$ data per period is summarized in Table 1. Nevertheless, for both trials, the P4 analyses were performed on mixed milk samples automatically collected from each milking following the procedure of the DHI protocol (ICAR, 2014). 
Table 1. Summary of the cow metrics included in both studies

Cow metrics (range, mean $\pm \mathrm{SD}$ )

\begin{tabular}{ccccccc}
\cline { 2 - 6 } Year & $\begin{array}{c}\text { No. of } \\
\text { cows }\end{array}$ & Age (yr) & Parity & DIM $^{1}$ & MY $^{2}(\mathrm{~kg})$ & $\begin{array}{c}\text { No. of } \\
\text { estruses }\end{array}$ \\
\hline 2016 & 16 & $1.9-4.4(2.7 \pm 0.7)$ & $1-3$ & $39-148(98 \pm 36)$ & $21.0-51.6(35.8 \pm 7.9)$ & $6.3-15.2(10.1 \pm 2.3)$ \\
2017 & 22 & $2.0-4.6(3.3 \pm 1.0)$ & $1-4$ & $52-294(130 \pm 64)$ & $20.5-57.6(36.3 \pm 8.8)$ & $5.2-23.5(12.2 \pm 4.6)$ \\
\hline
\end{tabular}

${ }^{1}$ DIM at the start of the trials.

${ }^{2}$ Average daily milk yield per cow during the trial.

${ }^{3}$ Average progesterone (P4) concentration per cow per milking over the full period.

${ }^{4}$ Number of confirmed estruses using method 1, 2, or both.

In 2016, the samples were frozen immediately at the experimental farm $\left(-18^{\circ} \mathrm{C}\right)$, whereas in 2017 , the samples were collected 3 times a week and brought to the Milk Control Center (Vlaanderen, Lier, Belgium). Here, 2-mL subsamples were frozen after analysis of the milk constituents. At the end of each trial, the P4 concentration of the thawed whole milk samples was measured with competitive ELISA, using a commercial milk P4 kit (Ridgeway, Gloucester, UK). The intraassay coefficients of variation were 29.4 and $7.8 \%$ (2016) and 22.9 and $12.5 \%$ (2017) for low and high controls, respectively. The interassay coefficients of variation were 43.8 and $19.7 \%$ (2016) and $38.0 \%$ and $18.5 \%$ (2017) for low and high controls, respectively. Although these coefficients of variation are high, they allow for clear discrimination between follicular and luteal P4 concentrations. A preliminary trial comparing with fresh and frozen variants of the same milk samples pointed out that there was no difference in P4 concentrations (results not shown). In both studies, the maximal sampling frequency resulted in on average 2.6 samples collected per cow per day. For further information on the sample collection, the $\mathrm{P} 4$ analysis, and its accuracies, the reader is referred to Adriaens et al. (2017).

Besides the milk P4 content, additional data of the cows were collected to confirm the onset of estrus, ovarian problems, or pregnancy. To identify estrus or ovarian problems, the ovaries were checked by an expert veterinarian using an ultrasound scanner (A6v, Sonoscape Medical Corp., Shenzhen, China) equipped with a L745V 46MM 7.5-MHz linear transducer. The frequency of ultrasound to confirm the presence of a preovulatory follicle, a corpus luteum (CL) or ovarian cysts depended on the sampling trial (2016 or 2017) and is explained in the following paragraphs. In addition, the uterus tonus was checked through palpation during rectal examination by the expert as described by Bonafos et al. (1995). A follicular cyst was defined as a follicular structure (cavity) larger than $20 \mathrm{~mm}$, either or not fully round and which persisted for more than $5 \mathrm{~d}$ on the ovaries in the absence of a CL, which was confirmed by the lack of serum $(<1 \mathrm{ng} / \mathrm{mL})$ or milk $\mathrm{P} 4(<5 \mathrm{ng} / \mathrm{mL})$. Luteal cysts were large structures $(>30 \mathrm{~mm})$ with thick walls and often a cavity, persisting on the ovaries for more than $5 \mathrm{~d}$ after the expected luteolysis, producing $\mathrm{P} 4$ and resulting on milk $\mathrm{P} 4$ being higher than $5 \mathrm{ng} / \mathrm{mL}$ for more than $23 \mathrm{~d}$. External estrous symptoms were scored visually, in particular the occurrence of standing heat, which typically occurs 26.4 $\pm 5.2 \mathrm{~h}$ (mean $\pm \mathrm{SD}$ ) before ovulation (Roelofs et al., 2005), and metestrous bleeding, which is indicative for the end of the estrous period. Pregnancy was confirmed 40 to $50 \mathrm{~d}$ after insemination by rectal palpation and ultrasonography (KX5200V scanner 6.5 MHz, Kai Xin, Jiangsu, China).

In 2016, the herd consisted of 52 lactating dairy cows. Two months before the trial, cows were selected based on their stage of lactation and reproduction status. Only animals not pregnant, cycling, and beyond the voluntary waiting period of $30 \mathrm{~d}$ at the start of the trial were eligible, leaving 16 cows in the study. To be able to closely monitor estrus even when no external estrous symptoms were displayed at the time of the trial (silent heats), the ovarian status of these cows was synchronized using the OvSynch protocol (Pursley et al., 1995). The collection of milk samples was started $4 \mathrm{~d}$ before the last GnRH injection. Sixteen days after the last $\mathrm{GnRH}$ injection, the ovaries of each cow were checked for the presence of a CL and luteal activity confirmed with a serum P4 sample $>1 \mathrm{ng} / \mathrm{mL}$. Starting from d 19 after the last GnRH injection (typically $18 \mathrm{~d}$ from the previous induced ovulation), the uterus tonus and the growth of a preovulatory follicle were monitored daily until disappearance of the follicle. Seven to $11 \mathrm{~d}$ after the disappearance of the follicle, the presence of a CL was checked to confirm ovulation (Roelofs et al., 2010). If abnormal structures (e.g., thick-walled structures or follicles $>20 \mathrm{~mm}$ ) were detected on the ovaries, daily scanning continued until confirmation of cyst and treatment.

In 2017, the herd consisted of 58 cows. Two months before the start of the sampling period, the 28 cows 
that were beyond the voluntary waiting period and not confirmed pregnant were selected. The cows suspected to have cysts based on $\mathrm{P} 4$ profile measured by the onfarm device were checked by an expert veterinarian and, if needed, treated. At the start of the trial, cows confirmed pregnant or those that did not (re)start normal cycling were excluded, leaving 22 cows. For these cows, the sampling rate of this on-farm device was increased to once a milking. During the trial, the resulting on-line updated (i.e., each time a new measurement became available) raw milk $\mathrm{P} 4$ profile was assessed visually to detect the moment at which a consistent drop toward concentrations under $5 \mathrm{ng} / \mathrm{mL}$ started, staying below it for a period of at least $24 \mathrm{~h}$. This moment was named the Herd Navigator P4-drop (HN-P4-drop) and indicates the possible onset of estrus. Accordingly, synchronization of ovarian status was no longer needed. Between 15 to $50 \mathrm{~h}$ after the HN-P4-drop, the ovaries were checked using ultrasonography for the presence of a preovulatory follicle. If the ultrasound image was not clear, scanning was continued daily upon detection of abnormalities or confirmation of ovulation. In the meantime, the uterus tonus was monitored. Between 7 to $11 \mathrm{~d}$ after the HN-P4-drop, the appearance of a CL confirmed ovulation.

Based on these data, confirmation of the onset of estrus was established in 2 different ways: (1) increased uterus tonus, showing a well contracted uterus upon rectal palpation (Bonafos et al., 1995) and absence of a CL, together with the presence of a preovulatory follicle of at least $13 \mathrm{~mm}$ diameter on one of the ovaries, which disappeared and was replaced by a CL on the same ovary 7 to $11 \mathrm{~d}$ later (method 1 ), in analogy with the method used by Michaelis et al. (2014); and (2) the expression of standing heat (method 2; Roelofs et al., 2010). All cows standing to be mounted were found to show metestrous bleeding 2 to 3 d later.

The available profiles were subdivided based on the presence of abnormalities detected by ultrasonography. Because in one case an abnormality occurred at the end of the trial, that profile was split up in 2 parts, either or not associated with the detected abnormality, and therefore included in the analysis twice. In this way, 33 normal profiles and 6 profiles from cows suffering from fertility issues were used to validate the developed system, originating from the 38 different cows. The P4 data of $50.3 \pm 4.7 \mathrm{~d}$ per profile were included in the analysis. On farm, a P4-based monitoring system would start sampling in the postpartum phase, and therefore, the developed system is designed accordingly. However, because we sampled cows that were already cycling, none of the available profiles started in this first phase and the data of the incomplete cycle preceding the first follicular phase had to be discarded. As a result, P4 data from $3.5 \pm 3.9 \mathrm{~d}$ were excluded from the analysis. This is not a requisite for an on-farm system, as its monitoring can be initiated in the postpartum anestrus phase.

In total, 35 estruses were detected manually using the reference methodology also shown in Table 1 . In 12 cases, both reference methods confirmed estrus. Twenty times only method 1 using ultrasonography counted (uterus tonus, preovulatory follicle, CL), whereas the other 3 cases were observed by method 2 (standing heat). Metestrous bleeding was noticed in $69 \%$ of the cases. From the 6 cows for which one or more fertility problems were detected, one cow first had a luteal cyst, which evaded spontaneously at the end of the trial. Another one was treated first for a follicular cyst and developed a luteal cyst hereafter. In 3 cows, a follicular cyst was identified and one animal displayed anestrus after showing a normal estrous cycle.

\section{On-Line Updated Model}

In Adriaens et al. (2017), a model to characterize the $\mathrm{P} 4$ cycle was established, using a combination of 2 sigmoidal functions, together referred to as the full model (Equation [1]). This model was developed and optimized on complete $\mathrm{P} 4$ profiles and was shown to be able to mathematically characterize the shapes and dynamics of the P4 cycle. As such, it is an offline model, not yet incorporated in a monitoring algorithm.

$$
[\mathrm{P} 4]=b_{0}+A \times\left[\frac{t^{C_{1}}}{B_{1}^{C_{1}}+t^{C_{1}}}-e^{-e^{C_{2} \times\left(B_{2}-t\right)}}\right] .
$$

Each increasing part of a cycle, corresponding to the growth of a CL associated with an increase in $\mathrm{P} 4$, is described by a positive Hill function, which is a symmetrical S-shaped function, characterized with parameters $B_{1}$ and $C_{1}$ (Equation [1]), slowly evolving from the basal to the maximal luteal $\mathrm{P} 4$ concentration. The decreasing part associated with luteolysis can be characterized by a negative Gompertz function $\left(B_{2}\right.$ and $C_{2}$ in Equation [1]), which also has a sigmoidal shape but with the inflection point closer to the upper asymptote. More specifically, $b_{0}$ is the baseline $\mathrm{P} 4$ concentration when no CL is present. $A$ represents the upper horizontal asymptote of the sigmoidal functions, and the $B$ and $C$ parameters define inflection points and slopes, respectively. The parameter $t$ represents the time within a cycle, starting from $t_{0}$ (i.e., parturition or the time of luteolysis of the previous cycle). In an on-line, onfarm system, this means that the time-parameter is set 
back to zero after a luteolysis is detected. For a more elaborate description of the mathematical model and its parameters and how these functions were chosen, we refer to Adriaens et al. (2017). Besides the full model describing the P4 estrous cycle, the other stages of the reproduction cycles can also be identified using $\mathrm{P} 4$, and as such, this model can be incorporated in a system to monitor the fertility status on farm. A general overview of this on-line updated system is given in Figure 1. So, the inputs for the on-farm monitoring system are the raw $\mathrm{P} 4$ values, from which 4 different stages can be deduced. Additional inputs are moment of parturition and inseminations.
(1) Stage $1=$ postpartum anestrus. After calving, $\mathrm{P} 4$ is produced only by the adrenal gland cortex, resulting in a low and constant basal milk $\mathrm{P} 4$ level, described as such by a constant $\left(b_{0}\right.$, upper panel, lightest gray in Figure 1).

(2) Stage 2 = luteal phase. With the onset of follicular activity, a dominant follicle will be selected and ovulates. The remaining theca and granulosa cells on the ovary form the corpus hemorrhagicum, which develops into an active CL producing $\mathrm{P} 4$. The corresponding increase in milk P4 from basal to luteal levels is described by an increasing Hill function. Each time a new

$$
[\mathrm{P} 4]=b_{0}+A \times\left[\frac{t^{C_{1}}}{B_{1}^{C_{1}}+t C_{1}}-e^{-e^{C_{2} *\left(B_{2}-t\right)}}\right]
$$

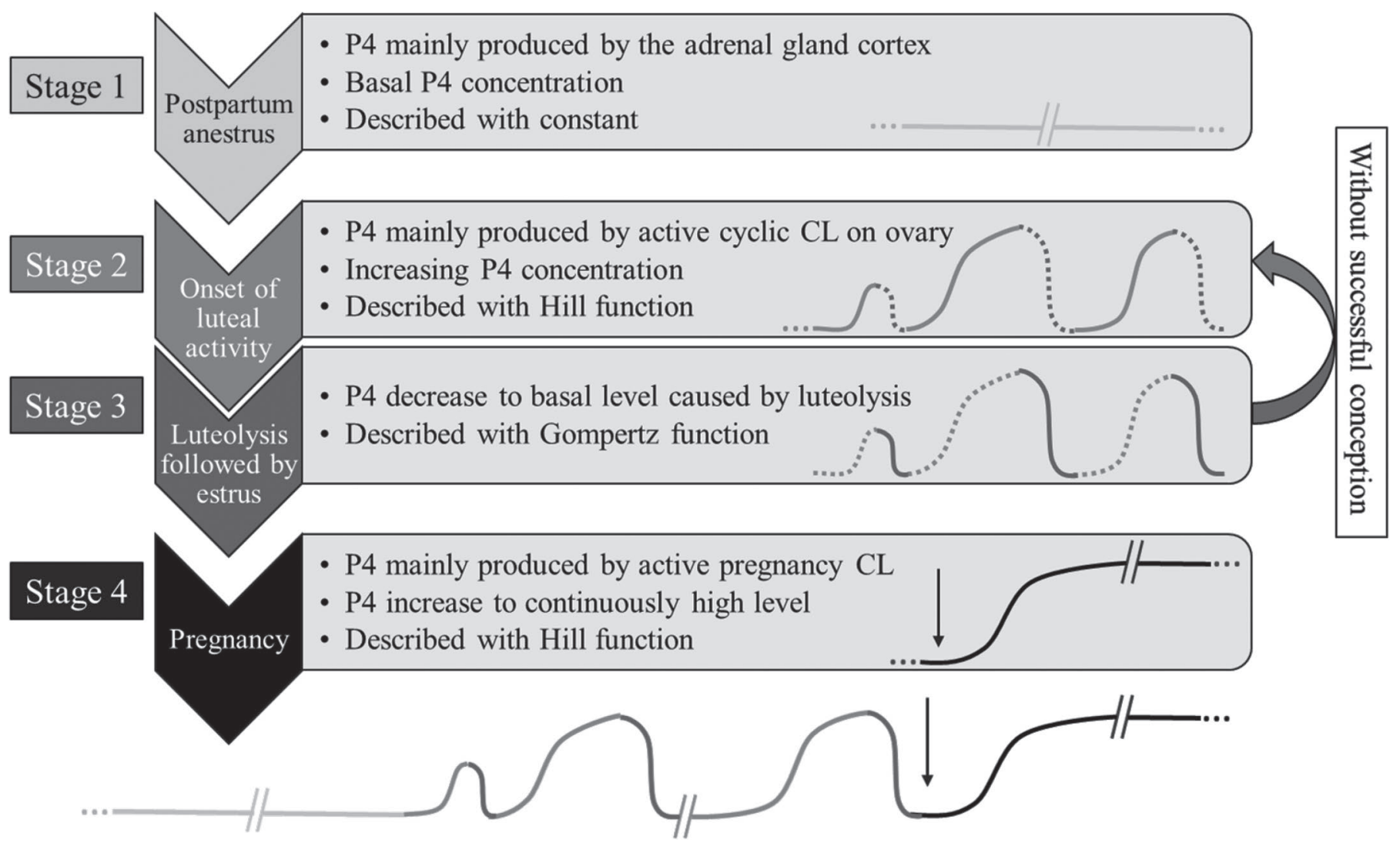

Figure 1. Different stages considered by the on-line updated on-farm monitoring system [i.e., postpartum anestrus; (light gray, stage 1), cycling (gray, luteal phase, stage 2, and luteolysis, stage 3) and pregnancy (black, stage 4)] and their link with progesterone (P4), the physiological characteristics, and the respective part of the mathematical model. The black vertical arrow indicates the moment of insemination resulting in pregnancy. $b_{0}$ is the baseline $\mathrm{P} 4$ concentration when no corpus luteum (CL) is present. $A$ represents the upper horizontal asymptote of the sigmoidal functions; the $B$ and $C$ parameters define inflection points and slopes, respectively; and $t$ represents the time within a cycle. 
measurement becomes available, the model parameters of the increasing function $\left(b_{0}, A, B_{1}\right.$, $C_{1}$ ) are recalculated (panel 2 in Figure 1, light gray).

(3) Stage $3=$ luteolysis. When luteolysis occurs, the P4 production rapidly decreases back to basal levels. At this time, the second part of the model (i.e., the decreasing Gompertz function, panel 3 in Figure 1, dark gray) is added to describe the $\mathrm{P} 4$ decrease and cycle characteristics can be calculated from the full model $\left(b_{0}, A, B_{1}, B_{2}, C_{1}\right.$, $C_{2}$; = combination of increasing and decreasing part). After luteolysis, the $\mathrm{P} 4$ concentration is low (follicular phase) and the dominant follicle can develop further toward a preovulatory stadium and consequently ovulate. Steps 2 and 3 are repeated, each time re-initializing the model parameters independent of the previous cycle, until a successful insemination establishes gestation.

(4) Stage $4=$ pregnancy. In this case, the increase in $\mathrm{P} 4$ production is not followed by luteolysis and the $\mathrm{P} 4$ concentration remains high (panel 4 in Figure 1, black).

Several events can disrupt the expected course of P4 in the different stages. When the onset of cyclicity is delayed, postpartum anestrus will be prolonged, detected by a lag in the first luteal activity after calving. In the same way, the presence of follicular cysts or unexpected anestrus during the cyclic phase can be noted after luteolysis. The typical duration of the follicular phase in which no active CL produces $\mathrm{P} 4$ and, accordingly, $\mathrm{P} 4$ is low, is 5 to $10 \mathrm{~d}$ (Royal et al., 2000). Longer periods of luteal inactivity after a detected luteolysis can indicate a problem for which a treatment may be required. A luteal cyst or a persistent CL will prolong the luteal phase of a cycle because luteolysis is prevented. On the contrary, when an insemination did not result in gestation, the present CL will regress after 15 to $40 \mathrm{~d}$ depending on whether or not conception occurred, and a new attempt for pregnancy can be made.

\section{Passing the Different Stages}

To determine the start of a new stage, an automated interpretation of the data is needed. The first stage ends with the onset of luteal activity corresponding to an increase in milk $\mathrm{P} 4$ is detected following a fixed rule, namely 3 measurements above $5 \mathrm{ng} / \mathrm{mL}$ within 3 d. A similar rule was used by Bruinjé et al. (2017b) who defined the onset of luteal activity as the first out of 2 successive measurements above $5 \mathrm{ng} / \mathrm{mL}$ following a measurement below $5 \mathrm{ng} / \mathrm{mL}$. This rule is considered sufficiently accurate because it is of no primary interest to know the exact starting moment of luteal activity on farm. The end of stage 1 corresponds with the beginning of stage 2 , being luteal activity.

In stage 2 , the model is only allowed to describe the increase in $\mathrm{P} 4$ during luteal development. Onset of stage 3 (i.e., $\mathrm{P} 4$ decrease preceding estrus) of the abovementioned process requires reliable detection of luteolysis and is the key part of the developed system. Therefore, its principles are elucidated in Figure 2 where the different steps are presented. In general, we modified a statistical control chart (CC) for individual subjects as described in Montgomery (2013) to suit our system, and used the principles for updating and recalculating model parameters as described in Mertens et al. (2009) and Huybrechts et al. (2014). Typically, the control limits of a CC for individual subjects are based on the moving range of successive measurements. However, we modified it to suit the need of detecting luteolysis, while being able to cope with the differing variability of the P4 measurements and possible outliers, and the large biological variation in the cycle characteristics. Overall, the CC consists of an upper (UCL) and lower (LCL) control limit, respectively given in Equations [2] and [3]. These UCL and LCL indicate when a measurement, in our case the P4 model residual, is out of the expected range (out of control) and action should be undertaken. For example, when the P4 measurement is below the LCL, the $\mathrm{P} 4$ value is thus unexpectedly low and luteolysis might be started. The UCL and LCL are initially calculated on a training period as described below depending on the stage, and updated each time a new observation becomes available.

$$
\begin{gathered}
\mathrm{LCL}_{i}=\min \left(-1 ;-3 \times \frac{\overline{\mathrm{MR}}_{i}}{d_{2}}\right), \\
\mathrm{UCL}_{i}=\max \left(1 ; 3 \times \frac{\overline{\mathrm{MR}}_{i}}{d_{2}}\right),
\end{gathered}
$$

In Equations [2] and [3], the $\overline{\mathrm{MR}_{i}}$ is equal to the mean moving range (MR) from the second observation until time point $i$ of that cycle for each pair of observations, starting from $t_{0+1}$ for each pair of observations $j$ and $j$ -1 given in Equation [4].

$$
\overline{\mathrm{MR}_{i}}=\frac{\sum_{j=2}^{i}\left|\mathrm{P} 4_{j, \text { res }, \text { corr }}-\mathrm{P} 4_{j-1, \text { res }, \text { corr }}\right|}{i-1},
$$

with $\mathrm{P} 4_{j, \text { res,corr }}$ as defined in Equation [5]. Only values within the control limits of a cycle are included in the 


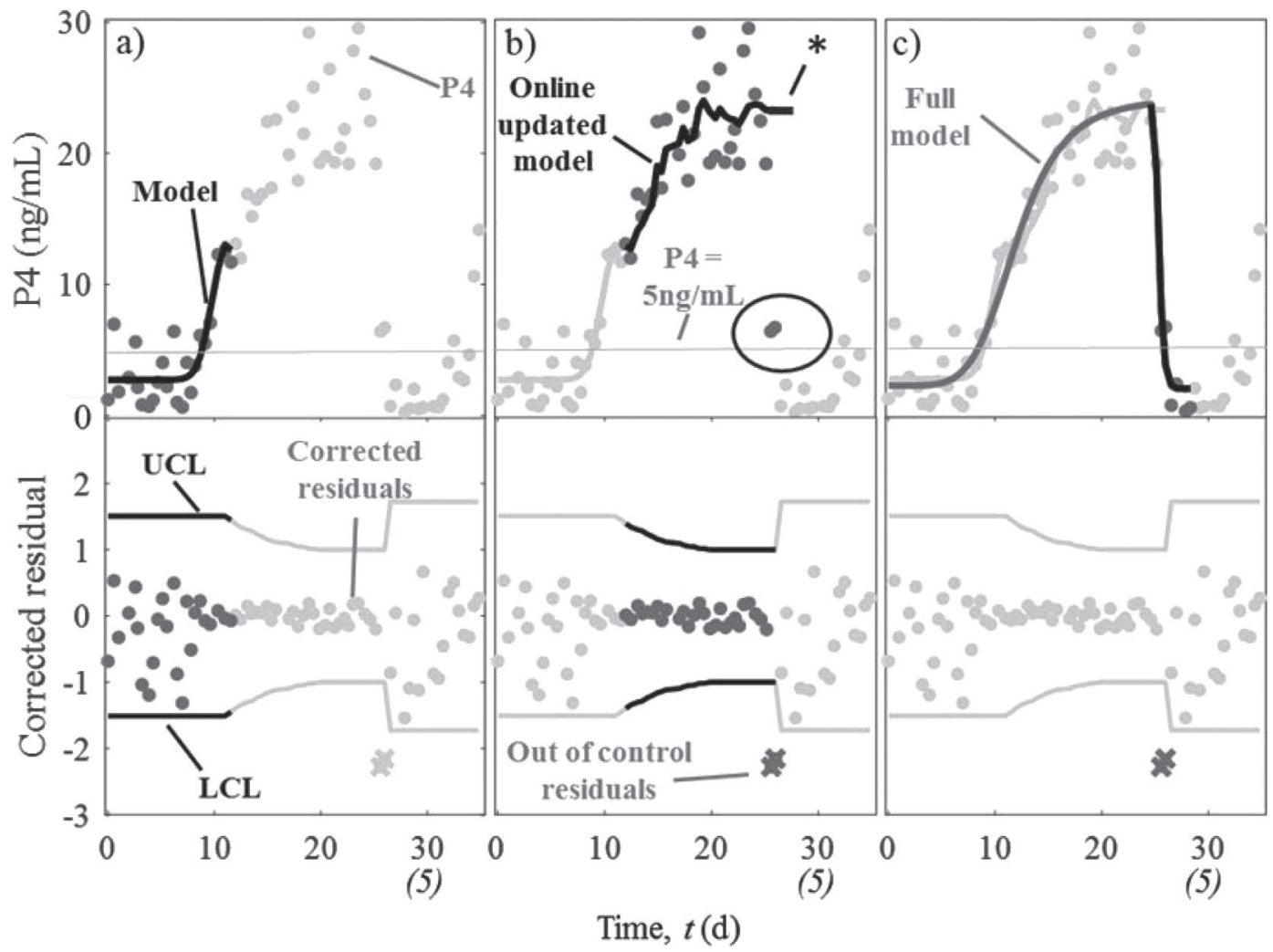

Figure 2. Overview of the different steps in detection stage 3 and transition stage 2 to stage 3, consisting of the on-line updated model and statistical control chart in the transition of stage 2 (onset luteal activity) to stage 3 (luteolysis) for one cow sampled once a milking. After a detected luteolysis, the time parameter is reset to zero and a new cycle begins. In the next $10 \mathrm{~d}$, progesterone measurements of this new cycle are collected and the increasing Hill function is fitted on the data (stage 2; shown in panel a). The control chart for the current cycle consisting of the corrected residuals, an upper (UCL) and a lower control limit (LCL) is initiated. Each time a new measurement becomes available, the model parameters are updated and the corrected residual is calculated accordingly (panel b). The jagged black line shows this model value after the updating procedure. If a residual is out of the lower control limit, the model parameters of the increasing function are fixed to the previous update, indicated with *. At the third measurement out of control $(\times)$, stage 3 (luteolysis) is initiated and the decreasing Gompertz function is added to the increasing function. This full model is then fitted on all available data (panel c). For this cow, the threshold of $5 \mathrm{ng} / \mathrm{mL}$ was not yet reached despite the confirmed luteolysis. The cycle characteristics might now be calculated from this full model. P4 $=$ progesterone.

analysis. The $d_{2}$ value for MR of paired observations is 1.128 (Montgomery, 2013). The minimum width of the control limits was set to 1 to avoid that phases with very low variability in the corrected residuals would make the $\mathrm{CC}$ too sensitive (e.g., due to saturation at very high $\mathrm{P} 4$ concentrations).

$$
\mathrm{P} 4_{j, \text { res.corr }}=\frac{\mathrm{P} 4_{j, \text { raw }}-\mathrm{P} 4_{j, \text { pred }}}{1+\mathrm{P} 4_{j, \text { raw }}}
$$

where $\mathrm{P} 4_{j, \text { res,corr }}$ represents the corrected residual at time point $j, \mathrm{P} 4_{i, \text { raw }}$ is the measured $\mathrm{P} 4$, and $\mathrm{P} 4_{j, \text { pred }}$ is the predicted $\mathrm{P} 4$ at time point $j$ by the Hill function describing stage 2 . The correction factor $\left(1+\mathrm{P} 4_{j, \text { raw }}\right)$ is included to account for the unequal variance in the $\mathrm{P} 4$ data, which is typically proportional with the $\mathrm{P} 4$ level (see also Friggens et al., 2008; Adriaens et al., 2017).
The constant 1 was added to avoid the denominator being smaller than 1, which would cause a large unbalance in the data. To make the concept more clear, the concrete steps are represented in Figure 2. These steps are repeated each time a new cycle is initiated by a stage 1 to stage 2 transition or a detected luteolysis $\left(t_{0}\right)$ :

- Panel a. Directly after the transition from stage 1 to stage 2, or a detected luteolysis, $10 \mathrm{~d}$ of new data are collected to initiate the CC. The stage 2 model (i.e., increasing Hill function + baseline) is fitted on the available data, and the corrected residuals are calculated as described in Equation [5]. The calculated UCL and LCL are applied on the full 10-d initiation period and out-of-control measurements are evaluated by checking whether the $\mathrm{P} 4_{j, \text { res,corr }}$ is above the UCL or below the LCL. 
The $\mathrm{P} 4$ data corresponding to residuals below the LCL are excluded from the calculations and the fixed initiation period control limits are updated if necessary.

- Panel b. After the initiation period, the model and control limits are updated/recalculated each time a new P4 measurement, in-control according to the previous model parameters, becomes available. When luteolysis occurs, the corresponding measurements are consistently below the LCL and thus the model is not updated. When a third consecutive measurement is below the LCL, luteolysis is considered confirmed at the first out-of-control measurement and stage 3 is initiated.

- Panel c. At the moment when the third consecutive measurement is below the LCL, the decreasing Gompertz function is added to the model resulting in the full model (Hill + Gompertz), for which the parameters can be calculated using all data available for the current cycle. This model is the final model for this cycle, and it is not updated anymore. Once luteolysis is confirmed, a farmer can be informed that the cow is likely to become in estrus and might be inseminated after waiting a certain period. At this moment, the cycle restarts and the first step is repeated as shown in panel a.

Figure 3 shows for one example cow that the corrected residuals meet the preconditions needed for data to be used in a CC, namely homoscedasticity, normality, stationarity, and the absence of significant autocorrelation. Especially, the homoscedasticity requirement (i.e., constant variance) is affected by the correction factor. In Figure 3, the raw residuals are shown as crosses and the corrected as circles. The upper panel (a) shows the residuals reflected against the fitted full model, representing the average $\mathrm{P} 4$ level. When the $\mathrm{P} 4$ level is low, the raw residuals have a low variance and are close to zero. In contrast, when $\mathrm{P} 4$ is high, the raw residuals show a large range and more variability. The applied correction flattens out this difference without limiting the sensitivity for low $\mathrm{P} 4$ values, shown by the circles varying within a constant range around zero. Stationarity is proven by the fact that none of the time-series of the corrected residuals of the on-line updated model had an intercept or slope significantly different from zero (average $P=0.404$ ). The Anderson-Darling test showed that the corrected residuals were not data extracted from a normal distribution (average $P<0.001$ ) for any of the cows. Both the normal probability plot (b) and the histogram (c) show that small residuals are overrepresented with a nonlinear pattern and deviat- ing Gauss-shape, respectively. Although normality is the least important condition for the $\mathrm{CC}$ to function properly (Montgomery, 2013), the overrepresentation of small residuals in our $\mathrm{CC}$ would lead to exceedingly narrow control limits. Therefore, the minimum width of 1 was set on the CC limits, as indicated in Equations [2] and [3]. The last panel of Figure 3 shows the sample autocorrelation plot (d) for 20 lags and its corresponding boundaries (Mertens et al., 2009). The lack of systematic crossing of these boundaries, both within a profile and between profiles, indicates the absence of significant sample autocorrelation in the data.

The onset of the last stage (i.e., pregnancy) is characterized by the absence of luteolysis within a predefined window following insemination.

The combination of data-engineering (model step) and a statistical process control chart is known as synergistic control (Mertens et al., 2009; Huybrechts et al., 2014). Therefore, our approach was named P4based Monitoring Algorithm using Synergistic Control (PMASC). All data processing was done in Matlab 2017a (Mathworks Inc., Natick, MA). The model was fitted and the parameters updated using a trust-regionreflective algorithm to obtain the least squares solution with a lower boundary of 0 for all the model parameters (cf. Coleman and Li, 1996).

\section{Monitoring Fertility}

The input of the on-farm monitoring algorithm is a time-series of P4 data of the same individual, further referred to as $\mathrm{P} 4$ profile. The CC-detected luteolyses were compared with the available reference data for onset of estrus, detected as described above. This means that a confirmed estrus should have been preceded by a detected luteolysis, which on its turn was followed by a consistent period of low $\mathrm{P} 4$ during the follicular phase of the cycle. Additionally, cows that were inseminated during this follicular phase and that did not experience a new luteolysis for more than $25 \mathrm{~d}$ after the previous one were assumed pregnant. Pregnancy was confirmed by ultrasonography 40 to $50 \mathrm{~d}$ after insemination. Ideally, the cow would be assumed pregnant if there was no luteolysis in a period of at least $35 \mathrm{~d}$ after insemination. However, the trial of 2016 ended earlier than 35 d after insemination for some of the cows. As we were not able to extend the data collection, this period was reduced to $25 \mathrm{~d}$, potentially having a negative effect on the specificity for pregnancy detection. Additionally, when an abnormality was noted, the obtained profile characteristics were also studied to verify whether the system can manage abnormal $\mathrm{P} 4$ patterns. 
Table 2. Overview of the detected estruses and applied reference methodology to confirm them

\begin{tabular}{lcccccc}
\hline \multicolumn{7}{c}{$\begin{array}{c}\text { No. of estruses detected by the algorithm and reference } \\
\text { methods used in practice, normal profiles }\end{array}$} \\
\cline { 2 - 7 } Year & $\begin{array}{c}\text { No. of } \\
\text { cows }\end{array}$ & $\begin{array}{c}\text { M1 } \\
\text { only }\end{array}$ & $\begin{array}{l}\text { M2 } \\
\text { only }\end{array}$ & M1 + M2 & $\begin{array}{c}\text { No } \\
\text { reference }\end{array}$ & Total \\
\hline 2016 & 15 & 6 & 1 & 6 & 5 & 18 \\
2017 & 19 & 14 & 2 & 6 & 10 & 32 \\
Total & 34 & 20 & 3 & 12 & 15 & 50 \\
\hline
\end{tabular}

${ }^{1}$ Method 1: uterus tonus, preovulatory follicle, corpus luteum.

${ }^{2}$ Method 2: standing heat.

${ }^{3}$ Luteolysis was detected but no data on method 1 or method 2 were available to confirm estrus.
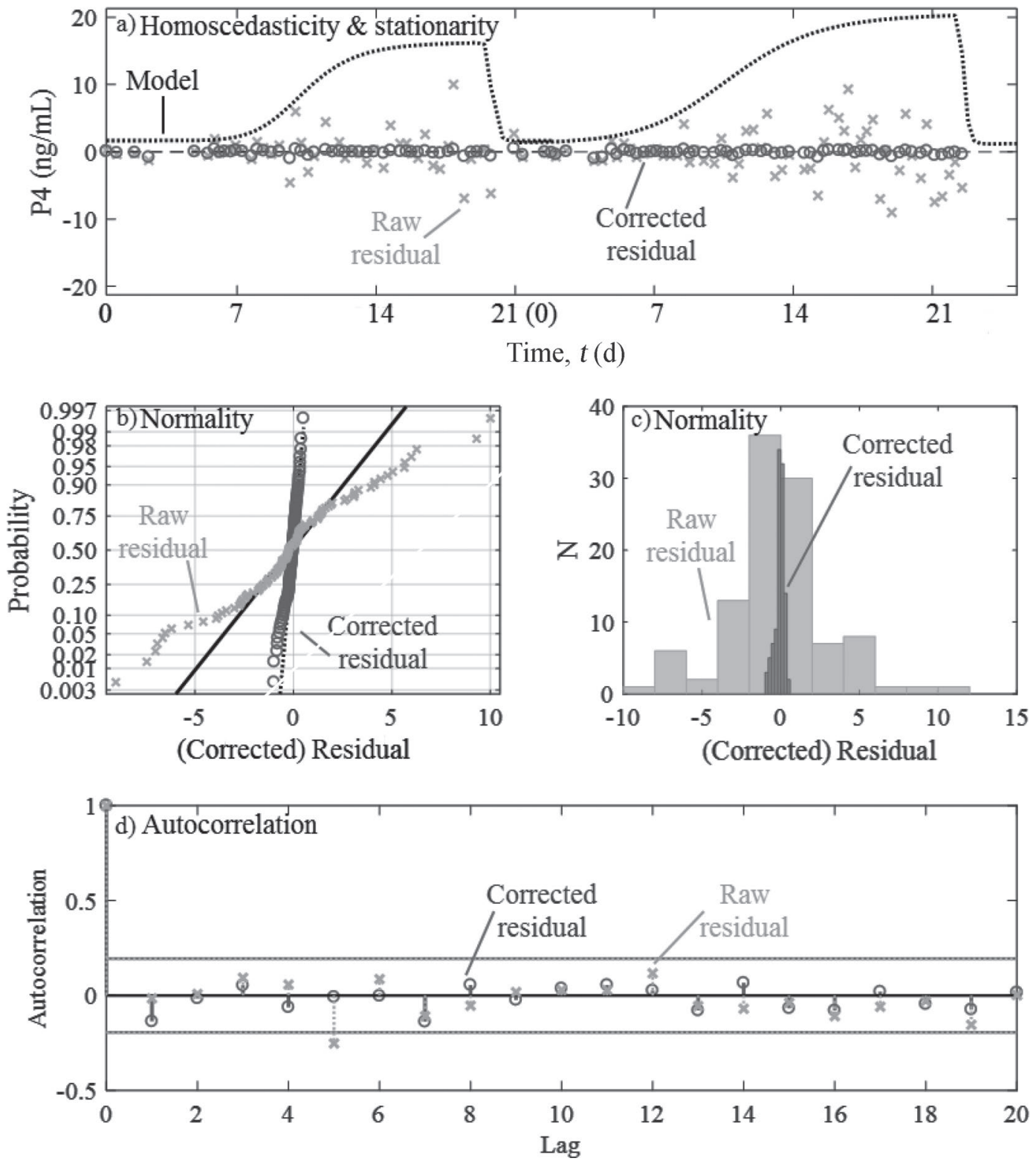

Figure 3. (a) The uncorrected residuals of the on-line updated model show the heteroscedasticity of the progesterone (P4) data proportional to the P4 level, represented by the model. The middle panels show the overrepresentation of small values in the corrected residuals, for which the minimum width of the control limits was set to 1 . No significant autocorrelation, as shown in panel d, is present in the data. 


\section{RESULTS AND DISCUSSION}

\section{Monitoring Fertility: Normal Profiles}

An overview of the luteolyses detected by the system and either confirmed or not using method 1, 2, or both methods is shown in Table 2. In total, 50 luteolyses across $34 \mathrm{P} 4$ profiles classified as normal were detected by the system.

For 15 of these detected luteolyses and subsequent follicular periods, we were not monitoring the cows to collect reference data, nor did the herdsmen note standing heat behavior. These cases thus occur in the first weeks of the $\mathrm{P} 4$ sampling periods when we did not have the cows synchronized yet (2016) or we were not monitoring the HN-P4-drop (2017). The other 35 cases were confirmed using method 1 or method 2 (see above). Briefly, for each case in which estrus was validated independently according to the reference methodology, the system provided timely detection of the luteolysis preceding ovulation. However, it should be noted that the number of cows for which reliable data were available was rather limited. These 35 cases are not enough to draw strong conclusions on the usefulness of the system. However, within the data available, this is a very good result that needs to be confirmed through further evaluation of the PMASC on larger data sets.

For 13 cows, a $\mathrm{P} 4$ decrease was not detected by the system within at least $25 \mathrm{~d}$ after insemination. Although $25 \mathrm{~d}$ might be too early to confirm pregnancy with high certainty, the absence of such a decrease confirms absence of a new estrus. It was shown before that the first 32 to $35 \mathrm{~d}$ of a pregnancy have the highest risk for embryonic death (Chebel et al., 2004; López-Gatius, 2012; Ricci et al., 2017), and accordingly, it is recommended to monitor the P4 profile for at least this period, and preferably longer. Twelve of these cows were confirmed to be pregnant in wk 6 of gestation. One cow turned out not to be pregnant at that time, but no further $\mathrm{P} 4$ data were available to confirm early embryonic death or a prolonged luteal phase as the milk P4 monitoring period stopped $26 \mathrm{~d}$ after insemination. The first estrus detected visually by the herdsmen for this cow was 59 $\mathrm{d}$ after the previous one noted by the PMASC system. Accordingly, this at least indicates that the developed system can deal with prolonged luteal phases after insemination, which could be related to pregnancy.

Next to identifying luteolysis and pregnancy, the model can also be used to calculate cycle characteristics from the model parameters. Typical model parameters are shown in Table 3. As such, the baseline and luteal P4 levels, slopes, and lengths of the different phases can provide monitoring information (Adriaens et al., 2017). For example, the average baseline concentration $\left(b_{0}\right)$ of
Table 3. Typical model parameters of the full model, fitted after detection of luteolysis to all data of a cycle

\begin{tabular}{lrrrrr}
\hline & \multicolumn{2}{c}{ Normal profile } & & \multicolumn{2}{c}{ Abnormal profile } \\
\cline { 2 - 3 } \cline { 5 - 6 } Parameter $^{1}$ & Mean & SD & & Mean & \multicolumn{1}{c}{ SD } \\
\hline$b_{0}$ & 1.9 & 0.7 & & 1.8 & 0.5 \\
$A$ & 19.1 & 6.2 & & 13.4 & 5.1 \\
$B_{1}{ }^{2}$ & 20.2 & 10.0 & & 28.4 & 11.4 \\
$C_{1}{ }^{2}$ & 13.8 & 15.5 & & 19.3 & 10.1 \\
$B_{2}{ }^{3}$ & 31.9 & 10.5 & & 40.2 & 8.3 \\
$C_{2}{ }^{3}$ & 4.7 & 4.7 & & 9.2 & 13.9 \\
\hline
\end{tabular}

${ }^{1} b_{0}$ is the baseline $\mathrm{P} 4$ concentration when no corpus luteum is present. $A$ represents the upper horizontal asymptote of the sigmoidal functions, and the $B$ and $C$ parameters define inflection points and slopes, respectively.

${ }^{2}$ Parameter values of the increasing Hill function.

${ }^{3}$ Parameter values of the decreasing Gompertz function.

the $\mathrm{P} 4$ profiles in this study was $1.9 \pm 0.7 \mathrm{ng} / \mathrm{mL}$ (mean $\pm \mathrm{SD}$ ), whereas the average maximal $\mathrm{P} 4$ concentration in the luteal phase $\left(b_{0}+A\right)$ was $20.9 \pm 6.1 \mathrm{ng} / \mathrm{mL}$, which is in accordance with the profile characteristics reported by Blavy et al. (2016). The average slope of the increasing part of each cycle $(3.1 \pm 2.5 \mathrm{ng} / \mathrm{mL}$ per day) is less steep compared with the decreasing part $(31.2 \pm 31.8 \mathrm{ng} / \mathrm{mL}$ per day). As such, the time in which the P4 level increases from a mean baseline of $1.9 \mathrm{ng} / \mathrm{mL}$ to a mean maximal level of $20.9 \mathrm{ng} / \mathrm{mL}$ is on average $6.05 \mathrm{~d}$. In contrast, the time in which the P4 level drops from maximal to basal $\mathrm{P} 4$ concentrations is only $15.5 \mathrm{~h}$ on average, indicating the high rate at which the P4 levels drop after luteolysis. Both observations are in line with previous research on plasma $\mathrm{P} 4$ concentrations (Mann, 2009; Meier et al., 2009).

Although good results were obtained with the PMASC, the following aspects of the methodology might need further investigation and optimization: (1) the apparently arbitrary use of the rule to start stage 2 ; (2) the need for 3 observations out of control for confirmation of luteolysis and (3) the use of a complete, once-a-milking sampling scheme. The first aspect concerns the transition from stage 1 (postpartum anestrus) to stage 2 right at the onset of first luteal activity. Because our methodology does not apply smoothing, raw $\mathrm{P} 4$ measurements determine the start of luteal activity and accordingly, the increasing part of the model. As a result, when the raw data accidentally fulfil the conditions set for initiating stage 2 , the increasing model might be fitted and updated while there is no actual luteal activity yet. Nevertheless, in that case, the residuals of the model are typically not large enough to provoke an indication of luteolysis in the CC. Consequently, this is not causing any problems in the studied cycles. When after a certain period luteal activity properly starts, the model parameters will 
adapt and the correct information can be extracted. Potentially, a possible improvement of the model might be to fix the $b_{0}$ parameter from the time luteal activity is confirmed, but this was not yet tested. Analyzing the parameter values changing over time during the updating procedure for the example shown in Figure 2 , we see that $b_{0}$ varies only little (window 1.3-1.8 $\mathrm{ng} / \mathrm{mL}$ ), whereas the asymptotic parameter $A$ shows considerable variation evolving from 6.4 to 14.8 (ng/ $\mathrm{mL}$ ), which is in accordance with the luteal growth. The $B_{1}$ value, mainly reflecting translation of the inflection point over the t-axis only differs slightly (range 8.4 to 10.4 ), whereas the slope determining parameter $C_{1}$ shows more variation, indicating that the slope increases over time (range 20.5-7.4). Also, the evolution of these parameters reflect the developing CL.

Additionally, it should be noted that the first ovulation of a cow has already passed at the time the system detects the first luteal activity after calving. This is a general drawback of using P4 for fertility monitoring because luteolysis does not precede first ovulation and therefore the onset of follicular activity cannot be detected. Nevertheless, common dairy practice advises not to inseminate on this first ovulation after calving, thereby mitigating this drawback (Peter et al., 2009).

The second aspect concerns the use of 3 measurements below the LCL to confirm luteolysis and inform the farmer about a cow that comes in heat. Timely informing a farmer is necessary to enable optimal insemination timing, 24 to $12 \mathrm{~h}$ before ovulation (Roelofs, 2005). However, Roelofs et al. (2006) also showed in their study that milk $\mathrm{P} 4$ dropped below a $5 \mathrm{ng}$ threshold at least $54 \mathrm{~h}$ before ovulation. Accordingly, we decided that using 3 measurements to ensure luteolysis is still in time, thereby minimizing the risk of false alarms. Concrete, we took into account that the time between milkings is generally $14 \mathrm{~h}$ or less. This means that luteolysis is notified by the algorithm within $28 \mathrm{~h}$ after the actual drop in $\mathrm{P} 4$ and on average about $30 \mathrm{~h}$ before ovulation (Roelofs et al., 2006), which is well in time. As such, the corresponding time lag on the notification of luteolysis does not outweigh the advantage of certainty and does not hamper the timely indication of the optimal insemination moment. Moreover, the indication of the moment of luteolysis itself is accurate, being independent of the time lag. Both luteolysis, which is at the moment of the first of 3 consecutive measurements with a residual below the LCL, as well as the model characteristics, can be used to predict the moment of ovulation. The latter possibly provides a large advantage compared with the use of a fixed threshold on a smoothed P4 profile, for which some difficulties are identified. For example, the smoothing introduces an unpredictable time lag on the moment at which the smoothed P4 profile drops below the fixed threshold, influenced by the sampling frequency and the rate of $\mathrm{P} 4$ decrease (Friggens et al., 2008; Bruinjé et al., 2017b). This might not influence detection of the follicular phase itself, but complicates the proper prediction of ovulation based on the moment of luteolysis. Using direct mathematical modeling of the $\mathrm{P} 4$ cycles, luteolysis might be characterized in a more consistent way. For example, in Figure $2 \mathrm{~b}$ the 2 measurements identified by the PMASC as out of control do not undercut a fixed threshold of $5 \mathrm{ng} / \mathrm{mL}$. Still, the luteolysis is detected as soon as the P4 concentration drops, independent of any predetermined fixed decision rules. Additionally, Friggens et al. (2008) observed that sometimes a higher threshold (e.g., $6 \mathrm{ng} / \mathrm{mL}$ ) is needed to identify high P4 estruses. This observation supports the idea of using an individualized approach rather than fixed thresholds. Accordingly, future research should further investigate the relation between luteal decay and ovulation and factors affecting this.

This brings us to the third aspect of the discussion on the use of maximum sampling frequency. In this study, all available data (i.e., P4 measured 2 to 3 times a day) were included in the analysis. However, to obtain a costeffective system, adjusting the sampling frequency dependent on the progress of the cycle would be preferred, as already implemented in the currently used on-farm monitoring algorithm (Friggens and Chagunda, 2005; Friggens et al., 2008). The principles from their approach might easily be integrated in the PMASC. For example, in the increasing phase of each cycle, which typically lasts for 10 to $20 \mathrm{~d}$, the sampling frequency can be reduced to once per $2 \mathrm{~d}$ or even less. When luteolysis is expected or when 1 measurement undercuts the LCL, the sampling frequency could be increased to once a day or at each milking. Future research should focus on the consistency of the model parameters and characteristics when sampling frequency is adjusted, but it is assumed that this system might be more robust against missing values in its decision making, compared with a smoothed level and fixed threshold. Depending on the practical decisions in this context and on-farm implementations, the PMASC monitoring system should be optimized accordingly.

\section{Monitoring Fertility: Abnormal Profiles}

It is important to illustrate that the developed PMASC has no problems with deviating fertility courses, which would limit the use of the monitoring system to model profiles only. Therefore, a few cases of fertility issues and the corresponding models are discussed in this paragraph. It is by no means our intention to describe at this point how the system can detect these 
fertility issues because the number of aberrant cases was too limited for a thorough validation. The conceptual framework described in Friggens and Chagunda (2005), in which the risk of luteal and follicular cysts is calculated based on the length of the luteal and follicular phases, could be applied on the profile characteristics calculated from the proposed approach as well. For example, the length of the follicular phase is typically 5 to $10 \mathrm{~d}$. When the $\mathrm{P} 4$ model does not reach luteal concentrations within an acceptable time period based on this knowledge, the risk of follicular cysts increases. The same reasoning can be applied to the luteal phase for luteal cysts or persistent CL.

To illustrate this concept and the applicability of our system for the detection of aberrant profiles, a P4 profile and the respective monitoring of a cow suffering with cystic ovary disease during the trial are shown in Figure 4. After detection of the follicular cyst, the cow was immediately treated with a GnRH-agonist inducing ovulation on d 22. Prior to the GnRH treatment, $\mathrm{P} 4$ was low and the corresponding baseline concentration varied around $1.5 \mathrm{ng} / \mathrm{mL}$ for more than $20 \mathrm{~d}$. No information was available for the preceding period, but based on these data, the follicular phase lasted for at least $22 \mathrm{~d}$. At that time, this cow had already been 103 $\mathrm{d}$ in lactation and seen in heat by the herdsmen 3 times. From the treatment day on, the milk P4 concentration increased slowly toward an intermediate luteal concentration of $12 \mathrm{ng} / \mathrm{mL}$. As this was a cow flagged for close monitoring, she was scanned repeatedly, and on the morning of d 27 after GnRH treatment, the presence of a luteal cyst was confirmed. At this moment, the cow was treated with dinoprost tromethamine, triggering
Table 4. Overview of the abnormalities

\begin{tabular}{lcccc}
\hline Year & $\begin{array}{c}\text { No. of } \\
\text { cows }\end{array}$ & $\begin{array}{c}\text { Follicular } \\
\text { cyst }\end{array}$ & $\begin{array}{c}\text { Luteal } \\
\text { cyst }\end{array}$ & Anestrus \\
\hline 2016 & 1 & 1 & 1 & 0 \\
2017 & 5 & 4 & 1 & 1 \\
Total & 6 & 5 & 2 & 1 \\
\hline
\end{tabular}

an immediate luteolytic reaction, reflected in luteolysis detected by the system in the afternoon on that same day. Although the P4 concentration of this cow was rather unstable, reflected in the high variability in the measurements during the luteal cystic phase, the system was able to identify the correct overall $\mathrm{P} 4$ pattern and as such, might be used to inform the farmer on deviating profiles and corresponding problems.

In total, from the 5 follicular cysts detected during the trials, 3 were preceded by luteolysis and indicated by the monitoring system. For the other 2 , the cyst was already present at the start of the trial and the proceeding luteolysis was outside the range of the data set. Two luteal cysts were detected from which one evolved to a follicular cyst spontaneously (serum $\mathrm{P} 4$ went from $4.6 \mathrm{ng} / \mathrm{mL}$ to $0.2 \mathrm{ng} / \mathrm{mL}$ ). An overview of these cases is given in Table 4 .

Although only a few cases were available and thus precaution should be taken when drawing conclusions, it was noted that the maximal luteal P4 levels for the cows suffering from fertility issues estimated by the model was significantly lower compared with the normal profiles ( 15.2 vs. $20.9 \mathrm{ng} / \mathrm{mL}$, respectively; $P=0.0197)$. This is in accordance with the observation of Hatler et al. (2003) and Rosenberg (2010), who

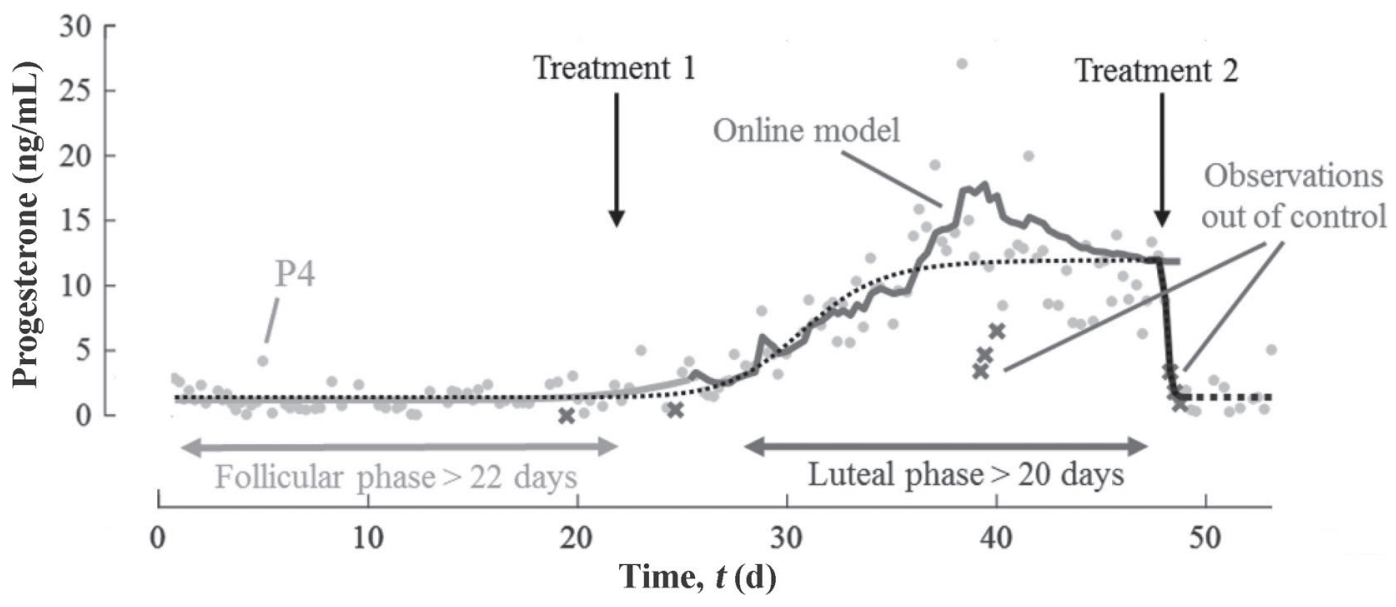

Figure 4. Example of the progesterone (P4) profile of a cow with cystic ovary disease. At the start, this cow developed a follicular cyst after a normal cycle. This was confirmed on d 22, and she was treated with a GnRH-agonist. Hereafter, the cow developed a corpus luteum (CL) producing P4, which evolved to a luteal cyst. This was treated with dinoprostum tromethamini on d 49, immediately followed by luteolysis detected by the system. During the cow's luteal cystic period, the P4 production seemed rather low and unstable, reflected in the residuals crossing the lower control limit boundary (e.g., around d 40). As these are interrupted with a high measurement, no luteolysis attention is triggered. 
reported that cows diagnosed with ovarian follicular cysts had intermediate concentrations of $\mathrm{P} 4$. This can be caused by an inferior quality of the CL. As seen in Figure 4, an irregular pattern of the milk P4 is noted. Several measurements undercut the LCL in the luteal phase of the cycle. Because these are interrupted by in-control measurement, they do not trigger the alarm for luteolysis. It seems likely that our system reacts more quickly and sensitively on actual P4 concentration changes compared with smoothing techniques. However, because most fertility problems affect the P4 profile in the long term, the real effect on detection rates should be further investigated by involving more cases and exploring the differences in profile characteristics and their predictive value for abnormal profiles.

\section{CONCLUSIONS}

We developed an innovative system for dairy cow fertility monitoring based on milk P4. This system is an alternative to the currently used filtering techniques and fixed thresholds for estrus detection and their associated problems. It consists of a mathematical model describing the $\mathrm{P} 4$ profile combined with a statistical control chart for the detection of luteolysis. The model characteristics and the control chart have the potential to identify first luteal activity, estrus, pregnancy, early embryonic death, and abnormal profiles indicating ovarian problems. As the approach is rather straightforward, it allows the implementation in an on-line updated monitoring system for on-farm use. Additional research is required to optimize sampling frequency, clarify the link between the model characteristics and the occurrence of abnormalities and to investigate the exact relation between the $\mathrm{P} 4$ profile and the time of ovulation.

\section{ACKNOWLEDGMENTS}

This work was supported by the Institute for the Promotion of Innovation through Science and Technology in Flanders, Belgium (IWT; IWT-LA project 110770). Ines Adriaens and Ben Aernouts are supported by the Fund for Scientific Research (FWO) Flanders, grant numbers $11 Z G 916 \mathrm{~N}$ and $12 \mathrm{~K} 3916 \mathrm{~N}$, respectively. We thank Carmen Adriaens (Laboratory for Molecular Cancer Biology, VIB Center for Cancer Biology, Leuven, Belgium) for critical reading of the manuscript.

\section{REFERENCES}

Adriaens, I., T. Huybrechts, K. Geerinckx, D. Daems, J. Lammertyn, B. De Ketelaere, W. Saeys, and B. Aernouts. 2017. Mathematical characterization of the milk progesterone profile as a leg up to individualised monitoring of reproduction status in dairy cows. The- riogenology 103:44-51. https://doi.org/10.1016/j.theriogenology 2017.07.040.

Blavy, P., M. Derks, O. Martin, J. K. Hoglund, and N. C. Friggens. 2016. Overview of progesterone profiles in dairy cows. Theriogenology 86:1061-1071. https://doi.org/10.1016/j.theriogenology.2016 .03 .037 .

Bonafos, L., K. Kot, and O. Ginther. 1995. Physical characteristics of the uterus during the bovine estrous cycle and early pregnancy. Theriogenology 43:713-721.

Bruinjé, T. C., M. G. Colazo, M. Gobikrushanth, and D. J. Ambrose. 2017a. Relationships among early postpartum luteal activity, parity, and insemination outcomes based on in-line milk progesterone profiles in Canadian Holstein cows. Theriogenology 100:32-41. https://doi.org/10.1016/j.theriogenology.2017.05.021.

Bruinjé, T. C., M. Gobikrushanth, M. G. Colazo, and D. J. Ambrose. 2017b. Dynamics of pre- and post-insemination progesterone profiles and insemination outcomes determined by an in-line milk analysis system in primiparous and multiparous Canadian Holstein cows. Theriogenology 102:147-153. https://doi.org/10.1016/ j.theriogenology.2017.05.024.

Chebel, R. C., J. E. P. Santos, J. P. Reynolds, R. L. A. Cerri, S. O. Juchem, and M. Overton. 2004. Factors affecting conception rate after artificial insemination and pregnancy loss in lactating dairy cows. Anim. Reprod. Sci. 84:239-255. https://doi.org/10.1016/j .anireprosci.2003.12.012.

Coleman, T., and Y. Li. 1996. An interior trust region approach for nonlinear minimization subject to bounds. SIAM J. Optim. 6:418445.

Friggens, N. C., M. Bjerring, C. Ridder, S. Højsgaard, and T. Larsen. 2008. Improved detection of reproductive status in dairy cows using milk progesterone measurements. Reprod. Domest. Anim. 43:113-121.

Friggens, N. C., and M. G. G. Chagunda. 2005. Prediction of the reproductive status of cattle on the basis of milk progesterone measures: Model description. Theriogenology 64:155-190. https:// doi.org/10.1016/j.theriogenology.2004.11.014.

Hatler, T. B., S. H. Hayes, L. F. Laranja da Fonseca, and W. J. Silvia. 2003. Relationship between endogenous progesterone and follicular dynamics in lactating dairy cows with ovarian follicular cysts. Biol. Reprod. 69:218-223. https://doi.org/10.1095/biolreprod.102 .012179 .

Huybrechts, T., K. Mertens, J. De Baerdemaeker, B. De Ketelaere, and W. Saeys. 2014. Early warnings from automatic milk yield monitoring with online synergistic control. J. Dairy Sci. 97:33713381. https://doi.org/10.3168/jds.2013-6913.

ICAR (International Committee for Animal Recording). 2014. ICAR Recording Guidelines. International Agreement on Recording Pract. 619. ICAR, Rome, Italy.

Inchaisri, C., R. Jorritsma, P. L. A. M. Vos, G. C. van der Weijden, and H. Hogeveen. 2010. Economic consequences of reproductive performance in dairy cattle. Theriogenology 74:835-846. https:// doi.org/10.1016/j.theriogenology.2010.04.008.

López-Gatius, F. 2012. Factors of a noninfectious nature affecting fertility after artificial insemination in lactating dairy cows. A review. Theriogenology 77:1029-1041. https://doi.org/10.1016/j .theriogenology.2011.10.014.

Mann, G. E. 2009. Corpus luteum size and plasma progesterone concentration in cows. Anim. Reprod. Sci. 115:296-299. https://doi .org/10.1016/j.anireprosci.2008.11.006.

Martin, O., N. C. Friggens, J. Dupont, P. Salvetti, S. Freret, C. Rame, S. Elis, J. Gatien, C. Disenhaus, and F. Blanc. 2013. Data-derived reference profiles with corepresentation of progesterone, estradiol, $\mathrm{LH}$, and FSH dynamics during the bovine estrous cycle. Theriogenology 79:331-343. https://doi.org/10.1016/j.theriogenology .2012.09.025.

Maselyne, J. 2016. Automated monitoring of feeding and drinking patterns in growing-finishing pigs: Towards a warning system for performance, health and welfare problems in individual pigs. $\mathrm{PhD}$ thesis. Department of Biosystems, KU Leuven, Belgium.

Mazeris, F. 2010. DeLaval Herd Navigator: Proactive Herd Management. Pages 26-27 in Proceedings of First North American Con- 
ference on Precision Dairy Management. Toronto, Canada, 2-5 March. http://www.precisiondairy.com/proceedings/s1mazeris .pdf.

Meier, S., J. Roche, E. Kolver, G. Verkerk, and R. Boston. 2009. Comparing subpopulations of plasma progesterone using cluster analyses. J. Dairy Sci. 92:1460-1468. https://doi.org/10.3168/jds.2008 -1464 .

Mertens, K., I. Vaesen, J. Löffel, B. Kemps, B. Kamers, J. Zoons, P. Darius, E. Decuypere, J. De Baerdemaeker, and B. De Ketelaere. 2009. An intelligent control chart for monitoring of autocorrelated egg production process data based on a synergistic control strategy. Comput. Electron. Agric. 69:100-111. https://doi.org/10 .1016/j.compag.2009.07.012

Michaelis, I., O. Burfeind, and W. Heuwieser. 2014. Evaluation of oestrous detection in dairy cattle comparing an automated activity monitoring system to visual observation. Reprod. Domest. Anim. 49:621-628. https://doi.org/10.1111/rda.12337.

Montgomery, D. C. 2013. Introduction to Statistical Quality Control. 7th ed. John Wiley and Sons Inc., Hoboken, NJ.

Pennington, J. A., S. L. Spahr, and J. R. Lodge. 1981. Influences on progesterone concentration in bovine milk. J. Dairy Sci. 64:259266.

Peter, A. T., P. L. A. M. Vos, and D. J. Ambrose. 2009. Postpartum anestrus in dairy cattle. Theriogenology 71:1333-1342. https://doi .org/10.1016/j.theriogenology.2008.11.012.

Pursley, J., M. O. Mee, and M. C. Wiltbank. 1995. Synchronization of ovulation in dairy cows using PGF2a and GnRH. Theriogenology 44:915-923.

Ricci, A., P. D. Carvalho, M. C. Amundson, and P. M. Fricke. 2017. Characterization of luteal dynamics in lactating Holstein cows for 32 days after synchronization of ovulation and timed artificial insemination. J. Dairy Sci. 100:9851-9860. https://doi.org/10.3168/ jds.2017-13293.

Roelofs, J., F. López-Gatius, R. H. F. Hunter, F. J. C. M. van Eerdenburg, and C. Hanzen. 2010. When is a cow in estrus? Clinical and practical aspects. Theriogenology 74:327-344. https://doi.org/10 .1016/j.theriogenology.2010.02.016.

Roelofs, J. B. 2005. When to inseminate the cow? Insemination, ovulation and fertilization in dairy cattle. $\mathrm{PhD}$ thesis. Wageningen Institute of Animal Sciences, Wageningen, the Netherlands.

Roelofs, J. B., F. J. C. M. Van Eerdenburg, W. Hazeleger, N. M. Soede, and B. Kemp. 2006. Relationship between progesterone concentrations in milk and blood and time of ovulation in dairy cattle. Anim. Reprod. Sci. 91:337-343. https://doi.org/10.1016/j .anireprosci.2005.04.015.

Roelofs, J. B. F. J. C. M. Van Eerdenburg, N. M. Soede, and B. Kemp. 2005. Various behavioral signs of estrous and their relationship with time of ovulation in dairy cattle. Theriogenology 63:1366-1377. https://doi.org/10.1016/j.theriogenology.2004.07 .009 .

Rosenberg, L. 2010. Cystic ovaries in dairy cattle. PhD thesis. Dairy Science Department, California Polytechnic State University, San Luis Obispo.

Royal, M. D., A. O. R. Darwash, A. P. F. Flint, R. Webb, J. A. Woolliams, and G. E. Lamming. 2000. Declining fertility in dairy cattle: changes in traditional and endocrine parameters of fertility. Anim. Sci. 70:487-501. https://doi.org/10.1017/S1357729800051845.

Rutten, C. J., A. G. J. Velthuis, W. Steeneveld, and H. Hogeveen. 2013. Invited review: Sensors to support health management on dairy farms. J. Dairy Sci. 96:1928-1952. https://doi.org/10.3168/ jds.2012-6107.

von Leesen, R., J. Tetens, W. Junge, and G. Thaller. 2013. Mathematical approaches to detect low concentrations in progesterone profiles. Animal 7:2008-2015. https://doi.org/10.1017/ S1751731113001754.

Walsh, S. W., E. J. Williams, and A. C. O. Evans. 2011. A review of the causes of poor fertility in high milk producing dairy cows Anim. Reprod. Sci. 123:127-138. https://doi.org/10.1016/j .anireprosci.2010.12.001. 